\title{
ANÁLISE DOS FATORES DETERMINANTES DA VIABILIDADE DE IMPLANTAÇÃO DO CONTRATO FUTURO DE SUÍNOS VIVOS NO BRASIL $^{1}$
}

\author{
Adriana Helena Gama dos Santos ${ }^{2}$ \\ Danilo R. D. Aguiar
}

Resumo - O objetivo deste estudo é analisar a viabilidade de utilização de um contrato futuro referenciado em suínos, no Brasil. O interesse decorre da importância da cadeia de suínos neste país, que, apesar de relevante, apresenta grande instabilidade, principalmente quando se avaliam os riscos de preços do produto. No entanto, a introdução de um novo contrato não é uma questão simples, visto que muitos contratos são lançados no mercado, mas tempos depois fracassam. Assim, o estudo do mercado e das características da commodity deve ser realizado antes da inovação contratual, para que os pontos positivos e possíveis pontos problemáticos sejam identificados. O modelo utilizado foi desenvolvido por Pennings e Leuthold (1999), que avaliaram as características micro e macro da tomada de decisão de uma inovação contratual. Avaliaram-se, principalmente, as características macro, sendo estudadas as variáveis: i) perecibilidade e possibilidade de a commodity ser estocada; ii) homogeneidade e capacidade de mensuração; iii) volatilidade de preço; iv) tamanho do mercado físico; v) grau de competição do mercado; vi) contratos à termo; e vii) competição com outros contratos. Os resultados permitem concluir, por um lado, que as variáveis ii), iv), v) e vi) podem ser os principais entraves a implantação de um contrato futuro referenciado em suínos vivos, no Brasil. Por outro, o mercado apresentou preços bastante voláteis e pequena possibilidade de utilizar contratos futuros alternativos, como o milho ou o boi gordo, pontos tidos como favoráveis ao processo de implantação de um contrato baseado na própria commodity.

Palavras-chave: Mercado futuro, suínos e inovação contratual.

\footnotetext{
${ }^{1}$ Parte da tese de Mestrado em Economia Rural pela Universidade Federal de Viçosa - Minas Gerais - da primeira autora.

2 Economista e Mestre em Economia Rural pela Universidade Federal de Viçosa. E-mail: drgama@hotmail.com.

${ }^{3}$ Professor Adjunto do Departamento de Economia Rural, Universidade Federal de Viçosa. Viçosa - MG. CEP 36570-000. E-mail: danilo@ufv.br.

Recebido em 03/03/2003 - Aceito em 14/04/2003
} 


\section{Introdução}

\subsection{Considerações iniciais}

Independentemente da atividade econômica em que uma empresa esteja inserida, verifica-se presença do risco que é inerente a toda e qualquer atividade. Especificamente na produção agropecuária, podem-se listar três tipos básicos de riscos: os riscos de produção, os climáticos e os de preço. Os dois primeiros podem ser minimizados pela utilização de seguros agrícolas, por exemplo. Já o risco de preços é tido como um dos principais problemas enfrentados pelos produtores agrícolas, o que faz com que careçam de mecanismos que possam reduzi-los. Os mercados futuros podem cumprir essa função, reduzindo o risco de preço da produção ou sinalizando para o mercado com uma formação de preços mais transparente. Isto permite que os preços futuros funcionem como base para a formulação dos preços para o mercado como um todo, podendo ser usado, inclusive, como base para as formações de preço das empresas do sistema integrado de produção.

As negociações de contratos futuros se dão nas bolsas de mercadorias, que são instituições que visam promover um local onde a transferência de risco entre os participantes do mercado possa ser realizada. São nelas que se disseminam as informações entre os membros do mercado e são formuladas estatísticas das comercializações efetuadas, permitindo que um ambiente competitivo seja estabelecido.

No Brasil, os contratos são negociados na Bolsa de Mercadorias \& Futuros de São Paulo - a BM\&F- fundada em 1991, pela fusão da Bolsa de Mercadorias de São Paulo com a Bolsa Mercantil e de Futuros. Em 1997, a então Bolsa de Mercadorias e de Futuros funde-se com a Bolsa Brasileira de Futuros (BBF), sediada no Rio de Janeiro. No final de 1999, assiste-se ao processo de abertura ou internacionalização da BM\&F, por meio do qual investidores estrangeiros podem passar a negociar contratos futuros de commodities agropecuárias. Em 2000, esta bolsa adere-se à Aliança Globex formada pelas bolsas de Chicago, Paris, 
Cingapura, Madri e Montreal, marcando a interligação eletrônica entre as bolsas aliadas e o processo de internacionalização de commodities agropecuárias. Com essa aliança, os investidores da BM\&F poderão negociar nas bolsas aliadas contratos agropecuários e outros tipos de contratos, ao passo que os investidores estrangeiros podem negociar apenas commodities agropecuárias.

Na BM\&F, até 2001, eram negociados contratos futuros de açúcar, álcool, algodão, boi gordo, café, milho e soja, e de contratos de opções de compra e venda de todas essas mercadorias. Outro aspecto relevante é que quase todos os contratos eram cotados em dólares americanos. As exceções eram o contrato de álcool anidro carburante e o novo contrato de boi gordo (com vencimento a partir de março de 2001), que são cotados em reais. No final de 2001, o contrato de milho passou a ser quotado em R\$. Em 2002, foram relançados os contratos de soja e de algodão e foram lançados os contratos de café conillon e bezerro.

\subsection{O problema e sua importância}

A utilização dos contratos futuros é ainda inexpressiva no Brasil, sobretudo quando se consideram os mercados de commodities agropecuárias. O país já contou com a negociação de contratos futuros de suíno vivo no final da década de 80, mas este mercado não obteve sucesso. Esses contratos, no entanto, têm sido utilizados nos Estados Unidos, sendo oferecidos pela Chicago Mercantile Exchange (CME) há mais de vinte e cinco anos. Desde então, vêm funcionando como importante ferramenta de gerenciamento de risco para os participantes do mercado de suínos norte-americano.

No entanto, a introdução de um novo contrato futuro não é uma questão de fácil resolução. Silber (1981) estudou as possibilidades de sucesso dos novos contratos que foram introduzidos, entre 1960 e 1980, nos Estados Unidos, tomando como critério de avaliação a situação deles três anos após sua introdução. Assim, considerou como bem sucedidos aqueles que, após este período, ainda continuavam no mercado. Do total de con- 
tratos analisados, apenas $42,9 \%$ obtiveram sucesso, ou seja, mais da metade deles fracassaram.

Isso faz com que o risco de fracasso de novos contratos seja de importância considerável, quando se avalia a introdução de uma nova commodity. Muitos deles fracassam na atração de novos participantes e, principalmente, na manutenção do volume de troca. Autores como Silber (1981) e Pennings e Leuthold (1999) salientaram que o desenvolvimento e a introdução de uma nova commodity são processos longos e caros, mas os fatores que influenciam o sucesso podem ser avaliados.

Diante disso, pretende-se estudar o mercado suinícola brasileiro, com vistas em avaliar a viabilidade de implantação de um mercado futuro, como alternativa para minimizar as incertezas associadas, especificamente, aos riscos de preço. O trabalho propõe-se a analisar a comercialização produtor-empresas de abate e processamento, onde se encontra um dos principais gargalos do sistema e onde os preços futuros podem funcionar como um sinalizador de preços para o mercado, inclusive para a formação de preços das agroindústrias. $\mathrm{O}$ estudo dos aspectos favoráveis e dos possíveis pontos de estrangulamento para a implementação desse mercado futuro é o problema principal ao qual este trabalho se propõe a investigar.

Especificamente, pretende-se:

a) Identificar as condições necessárias à implantação de um mercado futuro do produto e verificar se elas estariam presentes no mercado brasileiro;

b) Identificar os principais entraves ao desenvolvimento do contrato futuro de suínos no mercado brasileiro. 


\section{Características do mercado de suínos no Brasil e nos Estados Unidos}

No Brasil, a cadeia de suínos tem grande relevância, visto que envolve expressivo número de produtores que, em sua maioria, são pequenos, o que faz com que contribua para a geração de renda na economia. Gomes et al. (1992) salientaram que a importância da atividade vem não só do grande contingente de produtores envolvidos, como também do volume de empregos diretos e indiretos gerados (2,5 milhões somente no Sul e estados de São Paulo e Minas Gerais), e da capacidade de produzir grande quantidade de proteína de alta qualidade em reduzido espaço físico e curto espaço de tempo. O consumo per capita de carne suína ainda é baixo, quando comparado ao de países europeus, mas este reduzido consumo, em face à proteína de alta qualidade proporcionada pelo produto, sinaliza o potencial de crescimento de um mercado a ser explorado. Mas, acima de tudo, a suinocultura brasileira caracteriza-se por ser um mercado importante que tem passado por processos de fusões e reestruturações, mas que não dispõe de um mecanismo efetivo de mercado capaz de relativizar as oscilações de preço e os problemas de comercialização do sistema.

A produção de suínos ocorre em todas as regiões, mas ainda há muita discordância entre as estatísticas apresentadas, o que dificulta o mapeamento da atividade. Basicamente, o que diferencia a produção entre as áreas produtoras é o grau de tecnologia empregado, fator que repercutirá diretamente na produtividade alcançada. A Tabela 1 mostra os números brasileiros da suinocultura em 2000. O rebanho está concentrado, sobretudo, na região Sul do Brasil, onde está localizada 34\% da produção nacional. Em seguida, vem o Nordeste, com 24\%; Sudeste, com 19\%; Centro-Oeste com 15,5\%; e Norte, com 7,5\%. 
Tabela 1 : Os números da suinocultura brasileira em 2000

\begin{tabular}{cc}
\hline Região & Concentração do rebanho de suínos no Brasil \\
\hline Sul & $34 \%$ \\
Nordeste & $24 \%$ \\
Sudeste & $19 \%$ \\
Centro-oeste & $15,5 \%$ \\
Norte & $7,5 \%$ \\
\hline
\end{tabular}

Fonte: Paravisi (2000).

A produção apresenta-se bastante heterogênea, convivendo, lado a lado, sistemas modernos de produção com sistemas tradicionais. A produção suinícola da região Sul é a mais desenvolvida, usando técnicas modernas que provocaram o aumento da produtividade e a redução dos custos. Segundo Paulilo (1990), isto é resultado do sistema de produção integrado no qual contratos de produção e comercialização são utilizados para desenvolver a produção. Por eles, produtores e agroindústrias têm direitos e atribuições bem definidos. Do lado dos produtores, reduz-se a exposição aos riscos do mercado, garantindo a oferta do produto e, do lado da agroindústria, tem-se acesso à matéria-prima de maior qualidade e na quantidade necessária ao seu funcionamento. Nesse sistema, a formação de preços se dá sobre um preço-base, definido por cooperativas ou agroindústrias, mais um percentual que premia índices zootécnicos da produção como quantidade de carne da carcaça, por exemplo. Os estados do Sul são os grandes exportadores do produto, colocando-o nas regiões de São Paulo, Rio de Janeiro, Bahia, Minas Gerais e Ceará, as grandes importadoras nacionais.

Fora da região Sul, o que predomina é o mercado aberto, sendo a produção feita basicamente por produtores independentes, e onde o preço é a variável que se ajusta às exigências de compradores e vendedores. Em algumas localidades, os preços praticados pelos concorrentes são acompanhados pelas bolsas de mercadorias, que são reuniões de produtores de determinada região para definir o preço do produto a cada semana. 
Segundo Pinheiro (2000), o que norteia a definição de preços nessas bolsas é a procura percebida pelos produtores e, também, as ações estratégicas que visam obter resultados específicos no mercado. Exemplos desse tipo de comercialização ocorrem nas regiões de Ponte Nova e Belo Horizonte, em Minas Gerais, e em São Paulo, onde produtores e compradores se reúnem para garantir uma formação de preços mais justa que funcione como indicador de preços para o mercado, minimizando os riscos de oscilações de preços.

Nas regiões de mercado aberto, pode haver certa instabilidade gerada pela insegurança com a disponibilidade ou entrega do produto na época planejada para os frigoríficos e agroindústrias. Por parte dos produtores, há limitação de recursos de capital para manutenção da atividade ou para investimentos em infra-estrutura produtiva. Nesta estrutura, os recursos de capital são, geralmente, provenientes de recursos próprios ou de reinvestimentos feitos pelos próprios produtores.

Observa-se que, nas regiões de livre mercado do Sudeste e Nordeste do país, a produção localiza-se, geralmente, próxima aos mercados consumidores do produto, e não perto das fontes de carcaças utilizadas pelas estruturas de abate. Isto faz com que essas áreas sejam importadoras de suínos e carcaça dos estados do Sul do país. Na região Sul, tem-se grande concentração da produção, produz-se com custos menores, sendo o preço pago pelo quilo de carne suína naquela região, em determinadas épocas, cerca de $30 \%$ inferior ao recebido pelos produtores das áreas de livre mercado.

Mudando o foco da análise para o mercado norte-americano, com vistas em fazer um paralelo entre a situação brasileira e a naquele país, onde o mercado futuro de suínos já existe há algum tempo, verifica-se a ocorrência, nos últimos anos, de diversas modificações no desenho dos contratos futuros de suínos.

Nos Estados Unidos, o mercado futuro referenciado em suínos tem longa história de atuação. Neste país, a Chicago Mercantile Exchange (CME) ofereceu o contrato de suínos por mais de vinte e cinco anos, 
funcionando como importante ferramenta de gerenciamento de risco para os participantes do mercado. A princípio, o produto-base do contrato era o suíno vivo, que foi substituído, em fevereiro de 1997, pelo contrato de carne suína magra congelada. Assim, o contrato de carne suína passou a representar, mais de perto, a realidade do mercado americano (Leuthold e Distch, 1999).

Cerca de um terço da produção norte-americana utiliza algum tipo de contrato de produção e comercialização da produção, sendo estes um meio de reduzir os riscos de preços para os produtores, abatedouros ou empacotadoras (Grimes e Meyer, 2000). Isto ocorre porque a volatilidade de preços é bastante significativa e, desde 1999, assiste-se a uma tendência de queda nesses preços. A vantagem dessa estratégia, segundo Schnitkey (2001), está no fato de poder cobrir os custos variáveis da produção, e a desvantagem é que esses preços obedecem a níveis mais baixos, além de limitar a possibilidade de conseguir preços maiores, caso haja reversão do mercado.

\section{Metodologia}

\subsection{Modelo teórico}

A teoria que explica o sucesso e o fracasso de novos mercados futuros está nos estágios iniciais de desenvolvimento, o que gera controvérsias acerca dos fatores que a explicam e, principalmente, da possibilidade de as bolsas de futuros preverem, ou não, a viabilidade de uma inovação contratual. Desse modo, vários autores acreditam na hipótese de que as bolsas de futuros não dispõem de uma metodologia que permita avaliar a viabilidade de um contrato, baseando essa decisão nos custos sociais da inovação ou na correção dos erros cometidos no passado.

Foi a partir de Black (1986) que se teve notícia de uma teoria geral, na qual os fatores de sucesso e fracasso dos contratos financeiros foram medidos estatisticamente. Ela se propõe a analisar o assunto, reunindo 
os enfoques das características que a commodity deve ter para ser passível de sucesso, e de qual o melhor desenho que o contrato deve assumir no mercado.

Nota-se, ao analisar a literatura, que vários autores concordam que o volume de contratos negociados é a variável-chave na determinação do sucesso ou fracasso de um novo contrato. Um contrato de sucesso é aquele capaz de atrair o interesse dos participantes e mantê-lo no decorrer dos anos. Assim, determinar o sucesso ou o fracasso de uma inovação contratual consiste em avaliar os fatores que afetam o volume de contratos negociados e de contratos em aberto, fatores indicativos da liquidez do mercado.

O modelo de Pennings e Leuthold (1999) deu suporte à análise, sendo adotada, basicamente, a abordagem macro da tomada de decisão sobre a implantação de um novo contrato futuro. Dentro dessa abordagem, o enfoque concentra-se nas características da commodity e do mercado em estudo.

Essa abordagem de viabilidade de implantação de novos contratos futuros tenta delinear as características relevantes que a commodity deve perfazer para ser comercializada a futuro. No entanto, nota-se algum grau de flexibilidade nessas características, pois, em determinados mercados, nem todas elas são cumpridas, e nem por isto as commodities foram renegadas ao fracasso.

Desse modo, são selecionadas e analisadas algumas variáveis tidas como relevantes para o sucesso de um novo contrato futuro, como segue:

I) A commodity não pode ser altamente perecível e deve possibilitar a estocagem

Alguns autores argumentam que, para ser negociada a futuro, a commodity deve ser durável, permitindo o armazenamento. A razão está no fato de a estocagem ser responsável pela alocação intertemporal dos produtos, induzindo a negociação de contratos desenhados que trans- 
firam os riscos de preço.

II) A commodity deve ser mensurável e homogênea

Uma commodity é dita homogênea caso possa ser padronizada. Esta é uma característica importante, visto que permite que o desenho de contrato seja atrativo a um número cada vez maior de pessoas.

Outra questão que merece destaque é o grau de dificuldade em se utilizar uma medida padrão de mensuração. Uma commodity de difícil mensuração permite o aumento dos erros de avaliação do seu valor, exigindo que as bolsas estabeleçam medidas de controle que, obrigatoriamente, incorrem em custos.

\section{III) Os preços no mercado físico devem apresentar-se voláteis}

A volatilidade de preços no mercado físico é tida como um dos principais fatores motivadores para utilização de um hedging no mercado futuro, contribuindo também para maior possibilidade de lucro por parte dos especuladores. Isso acontece porque a volatilidade pode alterar a oferta e a demanda da commodity, aumentando o grau de incerteza dos preços, num momento futuro. Com isto, os hedgers sentirão necessidade de proteger-se, enquanto os especuladores verão a possibilidade de ganharem com as oscilações de preço.

\section{IV) A commodity deve apresentar amplo mercado físico}

Quanto maior o tamanho do mercado físico (produção e estoques) ou o tamanho do mercado disponível (volume comercializado, por exemplo), maiores as chances de um mercado futuro ser bem sucedido.

V) $O$ mercado não deve ter influências de forças externas

O mercado deve funcionar livremente sem influência de forças controladoras como aquelas estabelecidas pelos cartéis e monopólios ou pelo governo. A presença dessas forças pode conduzir à manipulação 
de preços das commodities, distanciando a formação de preços da forma competitiva.

Segundo Teixeira (1992), isto acontece porque, nos mercados futuros, a incerteza é negociada com relação aos preços futuros. Assim, a partir do momento em que essa incerteza é reduzida ou eliminada pela ação do governo ou esta ação modifica constantemente as características do mercado, não haverá condições para o sucesso de um contrato futuro.

\section{VI) Falhas na contratação a termo}

Para Telser e Higibothan (1977), a existência de um mercado futuro não se justifica apenas pela função de transferência de riscos, uma vez que os contratos a termo também a cumprem, em grande parte dos casos. Desse modo, a contratação a futuro só seria viável se os custos de sua utilização não suplantassem os custos de utilização dos contratos a termo.

\section{VII) Inexistência de um mercado alternativo}

O enfoque baseado no desenho do contrato, desenvolvido por Black (1986), procura determinar as características factíveis que o contrato deve perfazer para despertar o interesse dos participantes do mercado. Nesse sentido, deve ser observada a possibilidade de concorrência entre contratos negociados dentro de uma mesma bolsa ou em bolsas diferentes.

\subsection{Modelo analítico}

Este estudo analisa as características consideradas mais relevantes para a viabilidade do mercado futuro da commodity suínos no Brasil, tomando como referência as variáveis apresentadas no modelo teórico. Neste item, explica-se como essas variáveis serão medidas neste trabalho. 


\section{I) Perecibilidade e possibilidade de estocagem do produto}

A descrição do produto comercializado no mercado fornecerá suas características principais, no que tange ao grau de perecibilidade e possibilidade de armazenagem.

II) Homogeneidade e capacidade de mensuração

O exame das formas do produto comercializado no mercado brasileiro permitirá avaliar o grau de homogeneidade nele existente e as dificuldades principais encontradas na sua mensuração.

III) Volatilidade de preço

A volatilidade dos preços dos suínos no mercado a vista é calculada nas principais praças de comercialização do produto.

Utiliza-se o método de cálculo da volatilidade histórica que, segundo Silva-Neto (1998, p.99), consiste na utilização do desvio-padrão de uma amostra representativa dos preços do mercado, como segue:

$$
\delta=\sqrt{\sum_{i=1}^{n}\left(\mu-z_{i}\right) \frac{1}{n-1}},
$$

$$
z_{i}=\ln \left(\frac{p_{i+1}}{p_{i}}\right),
$$

em que

$\delta=$ desvio-padrão ou volatilidade;

$\mathrm{n}=$ número de observações;

$\mathrm{z}_{\mathrm{i}}=$ observação;

$\mathrm{p}_{\mathrm{i}}=$ preço do ativo;

$\mu=$ média da observação. 


\section{IV) Tamanho do mercado físico}

A evolução da produção brasileira de suínos é utilizada nesta análise. A suinocultura é estudada pelo ponto de vista da sua participação no agribusiness brasileiro, sendo analisadas variáveis como valor da produção e capacidade de abate e processamento.

\section{V) Grau de competição do mercado}

O percentual de participação ou volume de produção decorrente dos sistemas integrados de produção é uma das variáveis analisadas. A unidade de medida será o número de cabeças abatidas pelas principais empresas. A razão de concentração será calculada para as $r$ maiores empresas do país.

Quanto ao ambiente institucional, é avaliado o grau de intervenção das medidas governamentais no mercado de suínos, fator que poderia ocultar as regras das negociações.

\section{VI) Contratos a termo}

As formas de comercialização do produto brasileiro serão analisadas sob o ponto de vista da influência que poderiam exercer nas negociações a futuro.

\section{VII) Competição com outros contratos}

Tal critério será medido pelo cross-hedging de uma commodity que poderia concorrer com o contrato futuro de suínos. Nesta parte do trabalho, fez-se uma análise econométrica com base na efetividade do hedge $e^{4}$ com vistas em vislumbrar se a utilização do cross-hedging (ou hedge-cruzado) do suíno com produtos alternativos seria efetiva. A escolha dessas commodities alternativas é baseada na sua influência sobre a formação de preço do suíno, como é o caso do milho e do boi gordo. Para esta análise foram realizadas regressões por meio das quais

\footnotetext{
${ }^{4}$ Efetividade do hedge: é o grau de redução de risco de preço alcançado por um hedger. O hedge perfeito é aquele que reduz totalmente estes riscos, o que, na prática, é raro.
} 
se busca verificar se o cross-hedging sob o produto é, ou não, eficiente. Em caso negativo, ter-se-á mais um incentivo para que um novo contrato seja introduzido. Nesta parte, os dados utilizados serão basicamente secundários, obtidos de revistas especializadas, via internet ou de outras fontes que se fizerem necessárias

A efetividade varia de zero a um $(0 \leq e \leq 1)$, sendo máxima quando as mudanças dos preços a vista e futuros forem perfeitamente correlacionadas, e diminuindo à medida que diminui a correlação entre essas variáveis. Quanto maior for a correspondência entre o produto comercializado no mercado físico e o produto especificado no contrato futuro, maior tende a ser a correlação entre seus preços e mais efetivo tende a ser o hedge.

\section{Resultados da discussão}

\section{I) Perecibilidade e possibilidade de estocagem do produto}

A primeira variável analisada foi o grau de perecibilidade e de possibilidade de estocagem do produto. O suíno caracteriza-se por ser comercializado basicamente vivo, sendo uma mercadoria perecível e de estocagem difícil. Sua comercialização assemelha-se muito à do boi gordo, produto que é negociado na BM\&F. Para alguns autores, o fato de o produto ser perecível e de não permitir a estocagem, limita a sua negociação a futuro, mas isto não tem sido um empecilho à comercialização do contrato futuro de boi gordo na BM\&F, e nem foi um fator limitante na comercialização do suíno vivo nos Estados Unidos, por exemplo. Acredita-se que também não seria o caso do suíno vivo no Brasil.

Os contratos baseados em commodities não-estocáveis começaram a ser comercializados, nos EUA, na década de 60. No caso do suíno vivo nos EUA, o contrato, como o próprio nome diz, era referenciado no produto vivo e funcionou por mais de 25 anos. As mudanças no contrato ocorreram por causa das reestruturações na indústria de abate e 
processamento, que tem se integrado vertical e horizontalmente, principalmente a partir de 1995. O aumento das grandes ou megaestruturas fez com que o mercado passasse a demandar um contrato referenciado na carne suína magra congelada, como o pork bellies.

Os exemplos dos contratos futuros de boi gordo e do próprio contrato de suínos vivo norte-americano apóiam a tomada de decisão a favor da criação de um contrato futuro de suínos no Brasil. O sucesso neles obtido, apesar de serem mercadorias tidas como perecíveis e de difícil estocagem, não foram suficientes para inviabilizá-los.

\section{II) Homogeneidade e capacidade de mensuração}

A segunda variável analisada foi o grau de homogeneidade do produto e sua capacidade de mensuração. O produto brasileiro ainda é muito pouco homogêneo, visto que há diferenças sensíveis entre o produto obtido dentro das várias regiões do país. Mas nota-se que o produto comercializado é basicamente tipo carne, sendo o rebanho nacional, em grande maioria, desse tipo. O produto tipo carne pode ser utilizado, com grande adequação, tanto na produção de cortes quanto na produção de subprodutos como embutidos, salgados e defumados. Geralmente, são comercializados machos castrados ou fêmeas com idade por volta de seis meses.

Nota-se, entretanto, tendência de segmentação do mercado de suínos, em que, de um lado, tem-se um produto na faixa de $100 \mathrm{~kg}$, destinado ao consumidor in natura, e, de outro, um produto na faixa de $120 \mathrm{~kg}$, destinado ao processamento pelas agroindústrias. Essa segmentação pode ser fator limitante ao livre desenvolvimento do contrato, cabendo, aí, identificar qual segmento do mercado o contrato futuro seria destinado. Sabese, de início, que é impossível se ter um contrato futuro de sucesso capaz de combinar os interesses de todos os participantes do mercado. Quanto à falta de homogeneidade do produto comercializado, ela pode ser minimizada pela utilização de um contrato futuro que seja liquidado financeiramente. 
Outro problema sério enfrentado pela suinocultura brasileira é que parcela significativa da produção suína brasileira é abatida sem inspeção sanitária.

Quanto à possibilidade de mensuração, o animal vivo já é comercializado seguindo algumas normas. O tipo de medida mais comumente usado é a pesagem do animal vivo e eviscerado no local de abate, embora em alguns lugares já se note a presença da tipificação de carcaça. Geralmente, o animal é mantido um jejum de seis horas antes do embarque, o que garante um transporte mais limpo e menor oscilação de peso. Assim, acredita-se que a mensuração não venha a ser um problema no caso da existência de um contrato futuro referenciado em suíno vivo.

\section{III) Volatilidade de preços}

Outra variável analisada foi a volatilidade de preço do suíno nas principais regiões produtoras. O produto apresentou-se bastante volátil, sendo verificado que, nas áreas de sistema integrado de produção, a volatilidade dos preços apresentou-se menor do que nas áreas de livre mercado. Foi calculada também a volatilidade do preço a vista das principais commodities agrícolas comercializadas na $\mathrm{BM} \& \mathrm{~F}$; quando comparadas a elas, o suíno vivo apresentou volatilidade bem significativa, enquanto a carcaça apresentou-se com preços mais voláteis do que o suíno vivo.

Optou-se por estudar a volatilidade de preços do mercado brasileiro em algumas das principais áreas produtoras, tanto integradas quanto de mercado aberto. Calculou-se a volatilidade nos mercados de Campinas e Formiga, representantes do mercado aberto, e em Concórdia, caracterizada pelo sistema integrado de produção.

A volatilidade foi calculada, para cada ano, a partir de 1998, tanto para o suíno vivo quanto para a carcaça em Concórdia, Campinas, Formiga e em Belo Horizonte. Nota-se, aqui, o interesse principalmente na volatilidade do suíno vivo, que é o principal meio de comercialização do 
produto no país. O Quadro 1 transcreve os resultados obtidos nessas praças.

Quadro 1 - Volatilidade anualizada em 1998, 1999 e 2000 nas praças de Campinas, Formiga, Concórdia e em Belo Horizonte

\begin{tabular}{|c|c|c|c|c|c|c|c|c|}
\hline \multirow{3}{*}{ Ano } & \multicolumn{9}{|c|}{ Praças } \\
\cline { 2 - 8 } & \multicolumn{2}{|c|}{ Concórdia } & \multicolumn{2}{|c|}{ Formiga } & \multicolumn{2}{|c|}{ Campinas } & \multicolumn{2}{|c|}{ Belo Horizonte } \\
\cline { 2 - 9 } & Vivo & Carcaça & Vivo & Carcaça & Vivo & Carcaça & Vivo & Carcaça \\
\hline $\mathbf{1 9 9 8}$ & 17,43 & 17,68 & 20,94 & 24,08 & 20,72 & 26,01 & 16,67 & - \\
\hline $\mathbf{1 9 9 9}$ & 15,95 & 17,45 & 22,60 & 32,26 & 22,89 & 22,77 & 24,89 & - \\
\hline $\mathbf{2 0 0 0}$ & 12,32 & 34,56 & 27,76 & 27,88 & 21,12 & 33,85 & 20,19 & - \\
\hline
\end{tabular}

Fonte: Elaborada pela autora com os resultados do trabalho.

Quanto mais elevada a volatilidade, maiores as oscilações no preço do produto, o que justifica a utilização de mecanismos, no caso mercados futuros, que venham a reduzir esses riscos de preço. Nota-se que a volatilidade do suíno vivo, em Concórdia, é menor do que nas outras áreas de livre-mercado analisadas na região Sudeste. Assim, optou-se por calcular a volatilidade nos principais estados produtores de suínos no Brasil. Essa volatilidade foi calculada sobre o preço do animal vivo em 2000 e obtiveram-se os resultados apresentados no Quadro 2.

Quadro 2 - Volatilidade de preços nos principais estados produtores brasileiros, em 2000

\begin{tabular}{|c|c|c|c|c|c|c|c|}
\hline Estado & RS & SC & PR & SP & GO & MT & MG \\
\hline $\begin{array}{c}\text { Volatilidade } \\
\text { (em \%) }\end{array}$ & 17,39 & 16,08 & 21,06 & 35,64 & 30,74 & 20,02 & $32,22$. \\
\hline
\end{tabular}

Fonte: Elaborada pela autora com os resultados da pesquisa. 
Mas uma vez, verifica-se que nos estados do sul, caracterizados pelo sistema integrado de produção, a volatilidade anualizada em 2000 foi menor. Esse fator pode afetar a comercialização do produto a futuro, uma vez que a região participa, significativamente, do volume total produzido nacionalmente.

Assim, conclui-se que a volatilidade do mercado de suínos vivos, no Brasil, é significativa, indicando que produtores, agroindústrias de abate e processamento e intermediários estão muito expostos aos riscos de oscilações de preços. A volatilidade é um bom indicativo da necessidade de mecanismos de proteção contra os riscos de preço do mercado.

\section{IV) Tamanho do mercado físico}

O valor bruto da produção (VBP) de suínos é baixo, como demonstrado no Quadro 3, quando comparado com aquele alcançado pelas carnes de bovinos. Isto indica que aquele mercado não apresenta um tamanho de mercado grande como ocorre com o do boi. Quando comparado ao café, o tamanho do mercado é menor ainda, já que esse apresentou um VBP, em 2000, de cerca de 6,9 bilhões.

Quadro 3 - Valor bruto da produção das principais carnes no sistema brasileiro, nos anos de 1999, 2000 e 2001

\begin{tabular}{|c|c|c|c|}
\hline Produto & \multicolumn{3}{|c|}{ Valor Bruto da Produção em milhões de reais } \\
\hline & $\mathbf{1 9 9 9}$ & $\mathbf{2 0 0 0}$ & $\mathbf{2 0 0 1}^{*}$ \\
\hline Carne bovina & $14.492,4$ & $17.402,8$ & $17.691,8$ \\
\hline Suínos & $2.456,3$ & $2.843,7$ & $2.847,8$ \\
\hline & & & \\
\hline
\end{tabular}

Fonte: Boletim Informativo da CNA.

* estimativa para 2001. 
Nota-se, no entanto, pequeno aumento do valor bruto da produção de suínos, que pode ser registrado pelo aumento de 15,8\%, entre 1999 e 2000 , e confirmado pela estimativa para 2001. As grandes empresas de abate e processamento movimentam grandes somas de capital, enquanto do lado dos produtores há tendência à descapitalização, gerada, sobretudo, pelos baixos preços do produto na última década.

O país tem aumentado sua participação no mercado externo, exportando principalmente para Hong Kong (38,71\%), Argentina (28,62\%), Rússia $(18,20 \%)$ e Uruguai $(4,40 \%)$, a dados de 2000 . O volume exportado é pequeno, quando comparado com o de países como a Dinamarca, Estados Unidos e Canadá, que são os grandes exportadores mundiais, mas tem-se mantido com tendência de crescimento desde 1996, período em que, se comparado a 1999, houve elevação de 98,5\%. Quando se comparam os volumes exportados de 1995 e 1999, nota-se um aumento de $2,175 \%$, um dos maiores saltos registrados entre os países exportadores (ABIPECS, 2000).

A principal perspectiva para o crescimento está no mercado interno, uma vez que, no mercado externo, ainda se encontram barreiras fitossanitárias que restringem a entrada do produto brasileiro. $\mathrm{O}$ excesso de oferta mundial do produto é outro fator a ser considerado. Os principais compradores do produto brasileiro são Hong Kong, Países Baixos, Rússia e os parceiros do Mercosul, Argentina e Uruguai.

Paralelamente, assiste-se à tendência de concentração da produção em unidades produtivas maiores ou ainda à expulsão da atividade de pequenos produtores e daqueles menos eficientes. Assim, nota-se, pelos dados do Quadro 4, redução do número de granjas produtoras no Brasil. 
Quadro 4 - Redução do número de granjas produtoras no Brasil, no período de 1970 a 2000

\begin{tabular}{|c|c|}
\hline Anos & $\mathbf{N}^{\mathbf{0}}$ de granjas produtoras \\
\hline 1970 & 871.200 \\
\hline 1975 & 661.700 \\
\hline 1980 & 670.350 \\
\hline 1985 & 391.000 \\
\hline 1990 & 275.440 \\
\hline 1995 & 181.750 \\
\hline 2000 & 100.000 \\
\hline
\end{tabular}

Fonte: Elaborada pela autora com dados de Faccin (2000).

Concluindo, nota-se que o tamanho do mercado de suínos brasileiro é pequeno. Isso se explica pelas características da produção nacional, ainda em fase de transição para uma produção industrial, pelo pequeno consumo e pelo mercado externo ainda em vias de desenvolvimento. Quando comparado a mercados como o de suínos norte-americano, o tamanho do mercado brasileiro é muito pequeno. Essas características podem restringir a utilização de um mercado futuro referenciado no suíno vivo, pois, num mercado com pouco movimento, a utilização de contratos de produção e comercialização, como os que já vêm sendo utilizados, pode tornar-se a alternativa mais viável de comercialização.

\section{V) O grau de competição do mercado}

As quinze principais empresas integradas de suínos brasileiras concentraram, em 1999, 46,49\% do abate total, percentual praticamente o mesmo de 1998 e 2000. Assim, conclui-se que o mercado de suínos brasileiro é bem concentrado, dado que as cinco principais empresas de abate concentraram 34,7\% do total em 1999. Em 2000, somente as cinco maiores concentraram $37,05 \%$ do volume total abatido. 
Em comparação aos Estados Unidos, segundo Paarlberg et al. (1999), a realidade não é muito diferente. $\mathrm{O}$ abate de suínos neste país é caracterizado pela presença de pequeno número de firmas que concentram grande parte da produção, ladeadas por um grupo grande de pequenas firmas que contribuem pouco para a produção total. Os índices de concentração demonstram que o abate tem ficado mais concentrado desde de 1985. O índice de concentração do mercado indica que a participação das quatro e das oito maiores firmas aumentou. Em 1985, as quatro maiores firmas concentravam $32,2 \%$ do abate total e as oito maiores, $50,8 \%$. Em 1997, estes índices subiram para 54,3\% e 75,5\% respectivamente. Em relação ao Brasil, as firmas norte-americanas são mais concentradas, fator que neste mercado não tem sido grande empecilho ao desenvolvimento da comercialização a futuro.

Resumindo, tem-se, no Brasil, uma estrutura de produção de suínos que inclui muitos produtores, enquanto se caminha para uma concentração mais acentuada do abate em poucas e grandes empresas. $\mathrm{O}$ mercado tem até a participação de muitas firmas, mas que apresentam pequena participação sobre o abate total de cabeças de suínos, e poucas que concentram quase $50 \%$ do abate total. O mercado ainda apresenta pouco movimento quando comparado ao volume comercializado nos principais países produtores, mas tem potencial de crescimento.

Quanto à influência governamental, tem-se que, segundo Talamini (1990), a participação governamental na fixação de preços do suíno vivo ou da carne na suinocultura brasileira é historicamente pequena. A falta de regulamentação governamental no mercado de suínos brasileiro é um bom sinal da necessidade de mecanismos que venham a auxiliar os seus participantes na proteção contra os riscos de preço do produto. O mercado futuro pode também atuar no desenvolvimento do mercado físico, funcionando como um sinalizador para a formação de seus preços. 


\section{VI) Contratos a termo}

Grande parte da produção nacional é comercializada sob alguma forma de contrato, sendo a maioria dos animais oriundos das estruturas integradas de organização da produção existentes no sul do país. Segundo Faccin (2000), cerca de $50 \%$ do volume total da produção nacional é resultante de parcerias e contratos e, para o futuro, acredita-se no aumento desse percentual para algo em torno de 70 a $80 \%$. Esses percentuais são significativos, pois os produtores desse sistema negociam $100 \%$ de suas produções com as empresas integradoras. Sabe-se, por trabalhos anteriores (a exemplo de Alves, 1999), que os produtores integrados estão na atividade também por fatores culturais, tendo seus antepassados também participado desse sistema de comercialização. Muitos deles também não têm perspectivas de saírem do sistema porque temem a sobrevivência fora dele. Outra questão é o fato de que, se saírem do sistema de integração de uma empresa, dificilmente conseguirão voltar a ele ou se integrarem a outra empresa, uma vez que as empresas têm suas áreas de influência bem definidas. Falhas na contratação podem existir, mas fugir dela é uma questão complicada para muitos produtores. O próprio desconhecimento da comercialização a futuro, no mercado agrícola brasileiro, pode ser um empecilho ao seu desenvolvimento.

A partir da tendência de concentração da produção em unidades maiores, de uma melhor organização dos produtores, e da negociação de volumes maiores, a comercialização a futuro talvez possa ser uma alternativa para diminuir o gargalo existente entre produtores e empresas de abate no sistema brasileiro.

\section{VII)Competição com outros contratos}

Este trabalho avaliou, primeiramente, a commodity boi gordo, dado o volume significativo de contratos negociados no mercado brasileiro. $\mathrm{O}$ contrato do milho, criado em 1996, também pode ser uma alternativa àqueles que buscam proteção contra a oscilação de preços, embora menos provável, visto que o volume comercializado é muito pequeno e tem tendência declinante. A escolha do milho é devido ao fato de ser este um 
dos fatores que mais pesam na composição dos custos produtivos de suínos em qualquer lugar do mundo, principalmente no Brasil, onde a oferta do produto é insuficiente para atender à demanda do mercado.

Foi calculada a efetividade do hedging cruzado do produto com os preços do suíno vivo no mercado, merecendo destaque as principais praças de comercialização no país. Os resultados obtidos foram transcritos no Quadro 5.

Quadro 5 - Cálculo da efetividade do hedging para o suíno vivo nas praças de Concórdia, Belo Horizonte e Campinas

\begin{tabular}{|l|c|c|}
\hline \multirow{2}{*}{ Praça } & \multicolumn{2}{|c|}{ Efetividade do hedging do produto em \% } \\
\cline { 2 - 3 } & Milho & Boi gordo \\
\hline Concórdia & 18,81 & 3,9 \\
\hline Belo Horizonte & 11,13 & 21,32 \\
\hline Campinas & 19,04 & 3,84 \\
\hline
\end{tabular}

Fonte: Elaborada pela autora

Os resultados do Quadro 5 demonstram que a possibilidade de um hegding cruzado com produtos alternativos não é muito efetiva na defesa do produtor contra as oscilações de preços no mercado brasileiro. Com isto, tem-se um indicativo de que o contrato futuro de suínos possa vir a ser um bom instrumento de proteção de riscos de preço no mercado brasileiro.

\section{Conclusões}

No mercado brasileiro verificou-se que os produtores, intermediários e, em menor grau, os frigoríficos e agroindústrias estão expostos à grande instabilidade e a oscilações de preços do produto. O mercado apresenta volatilidade de preços bastante significativa, de um ciclo para outro, fator 
que coloca os participantes do mercado expostos a constantes riscos. Assim, buscou-se identificar os pontos que seriam favoráveis à implantação do contrato e aqueles que seriam negativos.

No geral, pôde-se verificar que o mercado de suínos brasileiro está em transição para um mercado mais eficiente e competitivo, e para uma estrutura de produção mais moderna. Este quadro, juntamente ao ambiente de maior estabilidade econômica pós Plano Real, indica a possibilidade de desenvolvimento de um mercado futuro de suínos. A pequena efetividade do hedge cruzado do produto com produtos negociados a futuro, boi gordo e o milho é outro fator favorável ao desenvolvimento do contrato. Pontos que, a princípio, seriam empecilhos, como o fato de o produto ser perecível e pouco homogêneo, poderiam ser solucionados, por exemplo, por meio de um contrato que fosse liquidado financeiramente. Além disto, a experiência de sucesso de contratos como o de boi gordo e de contrato de suínos norte-americano indica que certa flexibilidade das características da commodities e do mercado deve ser considerada.

Considera-se que o principal problema que possa haver esteja relacionado com o tamanho do mercado a vista brasileiro, considerado pequeno em frente às principais commodities agropecuárias, do que decorrem prováveis problemas de carência de investidores e elevada concentração do mercado. Já o fato de a primeira tentativa do contrato ter sido fracassada, acredita-se que desta experiência possa sair a correção para que os mesmos erros não venham a ser repetidos no futuro; por exemplo, aqueles contratos não utilizaram liquidação financeira, o que, como mostra o exemplo do mercado de boi gordo, pode ser essencial à viabilidade de contratos de produtos animais.

A análise sugere ainda que o enfoque macro, adotado neste trabalho, possa, por si, não ser conclusivo quanto à viabilidade, ou não, de uma inovação contratual. Isso salienta a importância de que esta análise seja conciliada com a análise dos fatores micro, ou seja, à investigação do interesse dos possíveis participantes do mercado quanto ao interesse em utilizá-lo, ou não, como ferramenta de redução dos riscos de preços, para que conclusões mais definitivas possam ser obtidas. 


\section{Referências Bibliográficas}

ALVES, R.C. A comunicação entre integradora e integrados: o caso da agroindústria suinícola no meio oeste catarinense. Viçosa: UFV,1999. 152p. Dissertação (Mestrado em Extensão Rural) Universidade Federal de Viçosa, 1999.

BLACK, D. Success and failure of futures contracts: theory and empirical evidence. New York: Salomon Brothers Center for Study of financial Institutions, 1986. 70p. (Monograph Series in Finance Economics, 1986-1)

BOLETIM INFORMATIVO DA CONFEDERAÇÃO NACIONAL DA AGRICULTURA. [20 de maio de 2001] . (http:// www.cna.org.br).

BOLSA MERCANTIL E DE FUTUROS - BM\&F. Resumo geral das operações. [04/11/2000]. (http://www.bmf.com.br).

FACCIN, M. Sistema de produção. $5^{\circ}$ Seminário Internacional de suinocultura. São Paulo. 8p. 2000.

GOMES, M.F.M.,GIROTTO, A.F., TALAMINI,D.J.D. et al Análise prospectiva do complexo agroindustrial de suínos no Brasil. Concódia: EMBRAPA - CNPSA, 1992. 108p. (EMBRAPA - CNPSA . Documentos 26).

GRIMES, G. e MEYER, S. 2000 Hog marketing contract study. University of Missouri and National Pork Producers Council. March 7, 2000.

LEUTHOLD, R.M. e DITSCH, M.W. Evaluating the hegde potencial of clean hog futures contract. 1999.

PAARLBERG, P.; BOEHLJE, M.; FOSTER, K.; et al. Structural change and market performance in agriculture: Critical issues and concerns about concentration in the pork industry. Dept. of Agricultural Economics. Purdue University. Staff paper 99-14. 1999. 
PARAVISI, W. Segredos da carne. Agroanalysis. Vol. 20. nº7. 15 de julho de 2000. p.45-46.

PAULILO, M.I.S. Produtor e agroindústria: consensos e dissensos. O caso de Santa Catarina. Florianópolis:UFSC, 1990. 182 p.

PENNINGS, J.M.E. e LEUTHOLD,R. Commodity futures contract viability: a multidisciplinary approach. Illinois. 1999.

PINHEIRO, L.L. Condicionantes da competitividade da suinocultura na zona da Mata Mineira. Viçosa: UFV, 2000. 115p. Dissertação ( Mestrado em Economia Rural) - UFV - Universidade Federal de Viçosa, 2000.

SCHNITKEY, G. Using the futures market in response to low market prices.[13 de fevereiro de 2001]. (http://www.// porknet.outreach.uiuc.edu).

SILBER, W. Inovation, competition, and new contract design in futures markets. The Jornal of Futures Markets. v.1, n. 2. 1981.p. 123155.

TALAMINI, D.J. Modelo de oferta de suínos para o uso em situação de deficiência de dados. Anais do XXVIII Congresso Brasileiro de Economia e Sociologia Rural. Florianópolis - SC. 273-296. 1990.b

TEIXEIRA, M.A. Mercados futuros: fundamentos e características operacionais. São Paulo: Bolsa de Mercadorias e futuros. 53p. 1992.

TELSER, L.G. e HIGINBOTHAN, H.N. Organized futures markets:costs and benefits. Journal of Political Economy, v.85, n.51, p.969-1000, 1977. 